ISSN 1112-9867

\title{
DESIGN HEALTH VILLAGE WITH THE APPROACH OF SUSTAINABLE ARCHITECTURE AND UTILIZATION OF INTELLIGENT PRINCIPLES
}

\author{
S. Hoseini ${ }^{1, *}$ and S. Teimory ${ }^{2}$ \\ ${ }^{1}$ Islamic Azad University of Mahallat Branch \\ ${ }^{2}$ Tehran University, invitee Islamic Azad University
}

Published online: 15 May 2016

\begin{abstract}
Health estates the residential complex is said to be health services to offer its guests This includes creating a natural environment and away from the pollution of urban life , traditional medical care, hydrotherapy, sports and recreation is that in certain cases it has been noted in the present study. Created centers of growth and development town planning in the areas of health, respectively .Cheetgar park west east Tehran despite the unacceptable nature along one of the most polluted parts of the country is and the ability to become the center of a highly advanced and visitors will be fille . he current project aims to show town of intelligent health and with regard to the principles of sustainability in point of special importance to people's health is raised and read Using town planning rules and principles of intelligent health with regard to user requirements in the complex approach we have to define the series in advance due to the transparency and the need to design spaces the dynamic light is significant, with precipitation of priority projects. The use of mechanical equipment, electronic and electromechanical date its intelligent design provides for .Create structures to increase user safety as well as attracting investment and making money the prevalence in different parts of the country can benefit. For people to have this design can be found in different locations accomplished and the success and benefits enjoyed it.
\end{abstract}

Keywords: Health; city health; smart; sustainability in architecture; architectural design.

Author Correspondence, e-mail: seyedasghar.hosseini51@gmail.com doi: http://dx.doi.org/10.4314/jfas.v8i3s.187 


\section{INTRODUCTION}

Challenges in the world have been caused, to think of ways to improve our current situation. This improvement in the socio-economic context is more important. The major challenges of climate change in human societies, Growing poverty, declining natural resources and an uncertain future, And energy ambiguous available.Leaders and scientists in all parts of the world, To seek new solutions for development.These solutions are all must meet the principles of sustainability. If we do not have the right strategies to improve the situation; there will be improving. Useful ideas for the development, it has three columns and essential part of sustainable cities.The three components must merge with each other to achieve perfection. Economy, environment and society of development cities.Consumers largest cities, Primary sources are the main producer of waste and pollutants, the high population concentration in them. According to UN figures, by 2014 about $\% 70$ of the population countries, developing were living in cities. These centers are the engine of wealth creation and, the country's economy.This led the long-term plans, each country is important.Competition in today's world to turn these centers, To areas of social development, Economic and environmentally friendly. In the meantime the health of residents, Is one of the main components.In order to achieve these objectives should be ensured, People's health is properly funded. The aim of this study is to find a solution, that could be part of sustainable cities and smart, for small and confined to the face, A small sample was designed in Iran. This design can be sent to improve the general conditions of residents, and thereby more willing to use them, it will find and principles employed. In order to achieve this goal, the main approach to investigate the possibility, the use of this structure in different regions of the world, Is the smart approach. The next step is to design a health city, in the selected area with the acquisition criteria, and we will take appropriate measures for it.

\section{STATEMENT OF THE PROBLEM}

Health, social purpose, and achieving it requires active and using, All resources and tools available to pursue. Previous experience has shown that health, Influenced by a complex set of economic factors, the social and environmental. Health goals as a component of development, Careful planning is required. Its importance in terms of health and economy, Health village concept is to create employment and income, its design is in place. Given the size and multiple goals village health program, Needs a structure that can meet these 
goals. In fact, expanded health programs villages, The World Health Organization's health projects in cities, and the concept of healthy cities program is that, urban environments are important, the health issues comprehensively through coordination and cooperation, between different agencies and organizations viewed. In a healthy city to improve and change health outcomes, Due to changes through social, environmental, economic, Mobile health is emphasized.

\section{BACKGROUND RESEARCH}

Current challenges facing our world is convinced, the structure and function, Social and economic systems here. Important and effective part in this decision, including climate change, the development of poverty, overuse of natural resources, and the future is uncertain and unstable energy used, Fakeh must be fully addressed. (United Nations, 2002) World leaders and scientists all agree on this issue, the time has come to create a new form suitable for concept development. Of course, this does not mean that, Guidelines and without change at our disposal, But also challenges and changes along with it in mind. (Lélé, 1991) Intelligent design principles appropriate to consider the health of the town, their cities are important pillars. The cities that could provide project implementation costs, and residents of cities often to fix your problem, city health to come. Both cities are too many negative points. Difficulties in the production of waste and pollutants at their sources is created, The dawn of environmental and health anomalies, Residents is. (Van Bueren et al., 2012; Campbell, 1997) Most importantly, changing a key role in the design, in the normal population, and flexible vision is a world in cities. (United Nations, 2010) cities require quick and appropriate efforts, the needs of their residents. These efforts have in various fields including, urban management and design tailored to their needs to be done. (Scott, 2001). In summary it can be said, our cities should be sustainable in terms of areas, Social, economic and environmental returns, It can be designed and functional areas, such settlements facilitated health. On the need to redefine urban functions, How to create and manage them, as well as sustainable urban development, Can be designed and innovative planning, Construction entered into the twenty-first century. (Stren, White \& Whitney, 1992) Yet still the optimal conditions and related strategies, Sustainable management that can compete with traditional methods, is not fully used. (Jabareen, 2006). This is partly due to vaguely defined, the concept of health is relatively new settlements, and have a complex system (Metropolitan) to be used. (Tanguay et al., 2010) Now uncertainty strategies, and 
designing effective and sustainable policies that, urban systems to promote a favorable position, and the lack of performance monitoring systems clear, and the progress of the design has created a big problem. (Satterthwaite, 1997). The flexible design of educational facilities, Service, convenience, flexibility means the ability to respond to growth areas, in various stages of training. In other words the ability to change the size to smaller and what is possible to outgrow. This variability may, Due to long-term or short-term needs occur. (Hosseini et al., 1394). In an effort to achieve sustainable cities, many governments' proposals in the field of smart, and the rest has been provided separate functions, that's because a lot of uncertainty and functions, in their various sectors, is still not economically feasible. That could be done for the national mega-projects, No projects in the field of smart, standard and small and ensure their applicability to accomplish. These projects are often time consuming, And significant costs to governments impose. (Jabareen, 2006) The program requires effective infrastructure, in the field of ICT and also, applied knowledge in the field of digital is the buildings. No one disputes settlement capabilities and health, And the use of smart approach, But there are fundamental questions that, the uncertainty and risk that at runtime, and applying these centers will be created. In general, you can use these applications with an integrated, with careful design and use it during a specified time, Evaluated. As a result of this study can be compared and assessed, the strengths and weaknesses centers to more confident that, And so were prepared to use them on a wider scale.

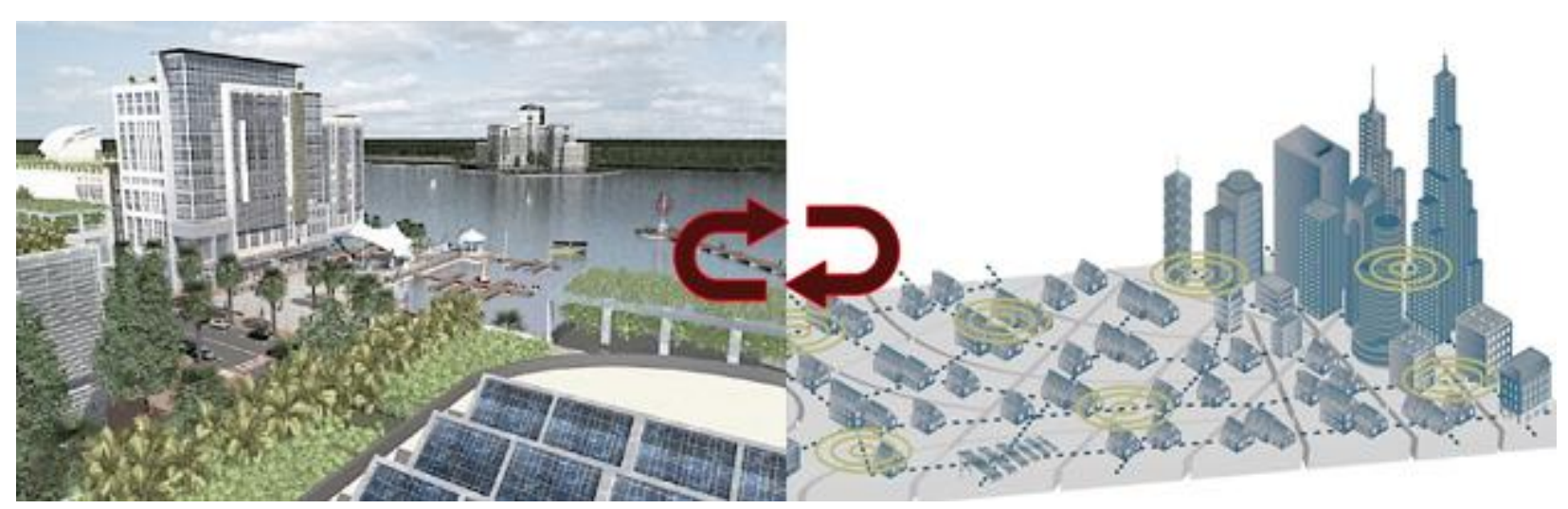

Fig.1. How the interaction between health and smart in building settlements. Is this approach can respond to human need? Where is definable relationship between the two? 


\section{TARGET}

The aim of this study was to clarify design concepts Town, for practical health and its relationship with the intelligent discussion. To achieve these objectives can be Different strategies to be considered. In fact, with the explicit design can be the power and appeal of different parts of the study, Health used in towns and cities. This could metropolitan decision-makers, Regional and provided guidance for the implementation of related tasks, And the possibility of implementing such a project in terms of design appropriate to specify requirements.

\section{PROCEDURE OF THE STUDY}

In this section complete description of the strategy and methods used, to achieve the research questions offered. Research in the field of architecture different ways and this choice depends on how you study and approaches. In order to clarify questions about how to do research, Business philosophy this season, And how to identify this technique delivers. The decision about what kind of study, and how to collect data, And Procedures The final process design and research will continue. At the end of the season the results to be expected, the results of this research are mentioned, the research examined the validity and reliability (Bryman, A. And Bell, E, 2007) It should be noted that today's cities, Mixture of various functions and operations, each of these functions is fit to play its role, the scale is determined, need space or the Earth. One of the major tasks of designers and urban planners, Allocation of land to different urban uses, Considering the role and function of the city, the city's economy, Social dimension as well as user interactivity on each other. Sort the various methods of zoning and land-use, Experienced in the history of urban planning, And barriers and benefits have been identified.User breakdown separating the various activities of the city and therefore, And create a separate function zoning, One of the common methods of zoning of the industrial revolution, The negative effects of this kind of attitude to the location of activities, During the specified time feedback theorists such as Jacobs, So that urban development sparked new ideas, Support of mixing applications, And consider it necessary for urban sustainability (Wahidi, Goldis, 1390 (. User mixing spaces downtown, Opportunities for human interaction and recreation, and enjoy the environment provides. In the last decade incorporation as component applications, Key in transit-oriented development, traditional neighborhood development, Intelligent and innovative urban development was discussed. User mixing essentially a form of urban development, Based 
on different user focus on a specific area.

User mixing concept, Promote sustainable forms of applications due to the shape of urban development, And in terms of urban planners, In fact, an important tool to achieve sustainable development.Health promotion could, lead to improved quality of life. Health Village is set, the main functions of improving the living conditions explain. In developing countries, efficient use of time and assets is very important. Our country because of its young population, to take advantage of this potential is great potential value. In each country's greatest asset are human resources. The world's largest human resource management in organizations, Using the principles and procedures, senior managers are the main priority. Can be used with a suitable environment, and health will be an optimal utilization of these assets. This will eventually improve the quality of life.

In addition to improving people's quality of life, economic earnings, Thereby achieving better facilities will be wise decision. Healthier society better meet their needs and, and in this way to achieve economic and social development. This relates to the creation of appropriate structures, and centralized user is reasonable in relation to the monuments, Will have the best performance and efficiency. As a result, a set of guidelines, to highlight the main areas of research activity is explained. These include the following:

1. Choose a location on the run, Texture and infrastructure necessary to create a complete health center, Which is integrated in the natural environment and does not harm it,

2. How appropriate design of buildings and installations, Organized and integrated design to ensure that, The current status and the ability to respond to the health needs of residents, 3 utilizes the principles of sustainability in all designs, In order to achieve the best interactions, Natural and synthetic man-made components,

4. The possibility of exploiting the principles of intelligent buildings, The structures created so that possibility, Control and optimization services and is also saving energy.

In order to understand the relationship between the designs of a health city, Where to seek work, the health of people can be, designing a health village with all the components needed to be considered. It is clear that the expected functions, and architectural spaces in the plan are not separable. This is especially when the use of space, In order to do different activities with a common goal done, is more important. Some researchers of this approach as, In order to optimize the mixing of land uses, Enjoying the facilities and site conditions to consider. Health Village is designed to be a suitable method, to deal with human health problems in today's society, and thereby enhance the quality of life of the society. In Figure 3-1, cans the 
process, we observed in the form of a model. It simply represents all the requirements, and requirements for conducting research. In this model system and a holistic view of, the project is intended, So that all parts of the project from the stage of ideas, to run and it is visible in one step.

\section{INTELLIGENT}

One of the challenges facing the energy crisis is architecture, And buildings with more than $40 \%$ of energy consumption play a decisive role, Are responsible for improving the situation in the future. The goal is to create intelligent building; the structure is safe and appropriate for users that are environmentally friendly. Strive for more energy efficiency in buildings, with the help of an acceptable solution is smart. One sign of intelligent systems increase productivity, designed to fit the environment and climate, where it is located. For this purpose the appropriate information with reviews, Microclimate characteristics and geographical conditions, Design to obtain (Di Zhang et al 2013). Equip public spaces for machinery, Public transport and distribution of spaces, Providing ease of monitoring citizens and visitors of the city, Due to the location and access to public spaces, Given that natural surveillance on public spaces, With the use of land facing the street and the park and warnings, Symbolic for control of space; Increasing access to assistance such as Add, The number of public phones in public spaces as well, Lighting equipment to the code and press them immediate relief. (Hosseini, SA, 1394). Brief History, intelligent buildings, in the early 1980s, came into existence. The New York Times article was referring to developers have created a new generation of homes. The houses were thinking for themselves, and smart buildings became known. The relationship between an old technology (construction management), and other new (telecommunications) was the emergence of these buildings. In Figure 2-5, you can overview See an intelligent building. In this image, the relationship between various components, and requirements for smart, Based on current expectations is shown (Di Zhang et al 2013). 


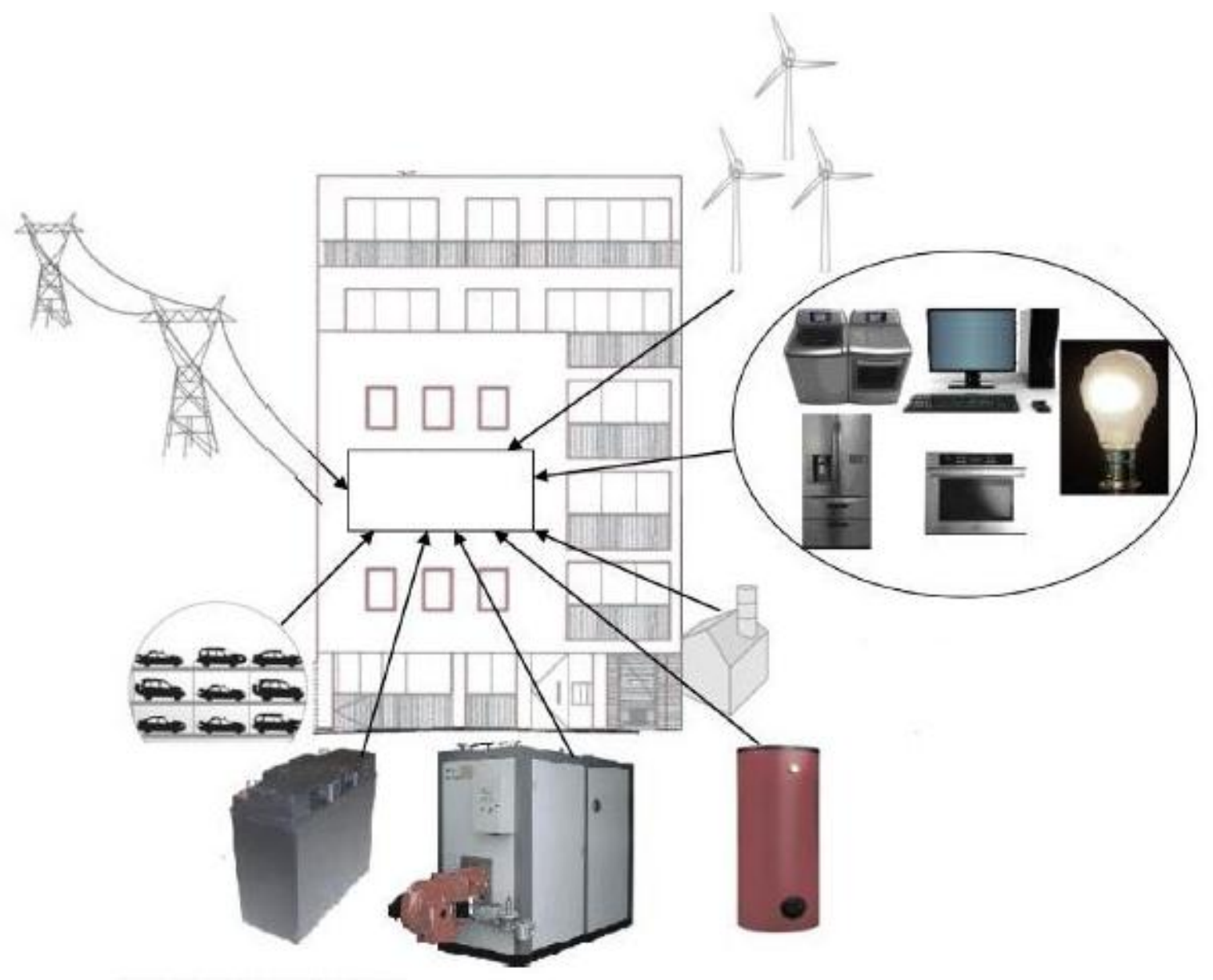

Fig.2. Overview of a smart building and its related components (Di Zhang et al 2013)

As you can see, intelligent building components and different sectors, and which are linked together can, to create a unified structure and fit. Without each of these components, Can not be called intelligent buildings. One of the main problems in this field, ignoring systemic thinking, is set to choose and smart buildings.In this case can not be the greatest efficiency, the costs and achieved initial investment. Smart buildings to install and use only, Technology or advanced technology is not limited to the day. Technology and systems in the building next are the enablers for achieving the goals. Our technology allows for more efficient use of the building, Provide safe spaces for users, Create a secure environment, increase energy efficiency, and finally we can move towards sustainability, to obtain a greater share of the housing market. In Figure 2-6, you can use a variety of technologies, See requirements in an intelligent building (Guan et al 2010). 


\section{PROJECT COMPONENTS}

Many changes occur in all stages of design, or build one of the main indicators of architectural projects, are these changes may be taken from the phase studies, To the design phase of any project there.The main reason for this can be applied to decisions, Various projects at various stages by different individuals, each role in the implementation of the project are searched.Given that each of these decisions, Taken in different parts of the project, And need not consider the other sectors, This can lead to a lack of integrity, Between the different sectors involved in a construction project.This lack of integration between the different parts,In addition to incompatibility, instability,Energy Losses and costs, increase operation time, In total, the project will be incurs a performance. (Hosseini, SA, 1394).

\section{INTELLIGENT BUILDING MANAGEMENT SYSTEM TASKS}

Mechanical and electrical control; lighting control systems; control air conditioning; fire alarm systems and smoke control; traffic control and protection; management elevators at certain times. In summary, one can find all content. And documentation is provided as a general diagram view. In this graph types can be different, Application of management techniques they see in cities. In this context, various enablers, and the flow of information is clearly marked.

There familiarity with a variety of smart, And the ultimate outcome of all these approaches to improve quality, Smart execution and lead in the study area.

\section{OVERVIEW SITE LOCATED IN DISTRICT 22 OF TEHRAN MUNICIPALITY}

District 22 of Tehran Municipality, northwest of Tehran, With an area of 6000 hectares and 30 hectares Privacy metropolitan area,Due to specific natural features and its position in the area of the capital,Prone area known as the hub of tourism, And its future prospects is based on this idea.

In terms of history, the history of the development of this area in 1349, Solar,And references to the area in the comprehensive plan of Tehran, Feder principle of District 22 in terms of having, Potential and actual environmental and structural diversity of land, On the one hand, and its vast untapped On the other hand, And in the absence of other parts of Tehran, Suffer from congestion and non-standard architecture, Has long attracted the attention of producers and urban affairs experts, Is located in District 22 of Tehran Municipality Ast4-2- general introduction site: District 22 of Tehran Municipality, northwest of Tehran, With an area of 
6000 hectares and 30 hectares Privacy metropolitan area,ue to specific natural features and its position in the area of the capital,

Prone area known as the hub of tourism, And its future prospects is based on this idea. In terms of history, the history of the development of this area in 1349, Solar, And references to the area in the comprehensive plan of Tehran, In the area 22 having the potential and actual environmental and the diversity of its vast pristine land on the one hand and on the other hand, While other parts of Tehran and the density and architecture, Custom suffer long consideration, Makers and experts in urban affairs has been.

\section{Introducing the site and the reasons for choosing it}

District 22 of Tehran Municipality between East lengths, "10" 551 "40 '20 51 northern latitudes,

"16 35 '32" 19 '57 35, in the northwestern city of Tehran, And downstream river basin and Vardij is located. The Alborz mountain area north of the center, In the East the rivers now, in the south of the Tehran-Karaj highway, And in the West with a range of forest planting Vardavard is limited, And the Tehran Municipality is contiguous zones 5 and 21, The northern boundary of District 22 of Tehran Municipality, The way to the southern slopes of Alborz, Has developed an elevation of 1,800 meters. Alborz Mountains over the last 30 years, the city attracts is, Such as crescent-shaped wall surrounding Tehran's geographical space, And the height of 1800 meters of steep, And bottlenecks in difficult mountainous barrier, Pose in front of city expansion. The highest elevation in area 22, above sea level in the direct line of the northern catchment area, Alborz Mountains in the East Village in Kyga with digital 3840 and the lowest point at a height of 1220 meters is the output arrow. This area is 54,000 ha, including the heights, the maximum length and width approximately equal to 26 and $17 \mathrm{~km}$. The distance is about 11 kilometers West zone to the beginning of Karaj. Ken river that flows from north to south, after the exit point across Asia, Groups plan drawn receptive surface waters, its eastern areas of the diversion channels, it is also to be connected. Vardavard north-south along the river, And parallel to the Kan River flows, And in the northern part of the West Central region extends, In the downstream, the west zone to form. 


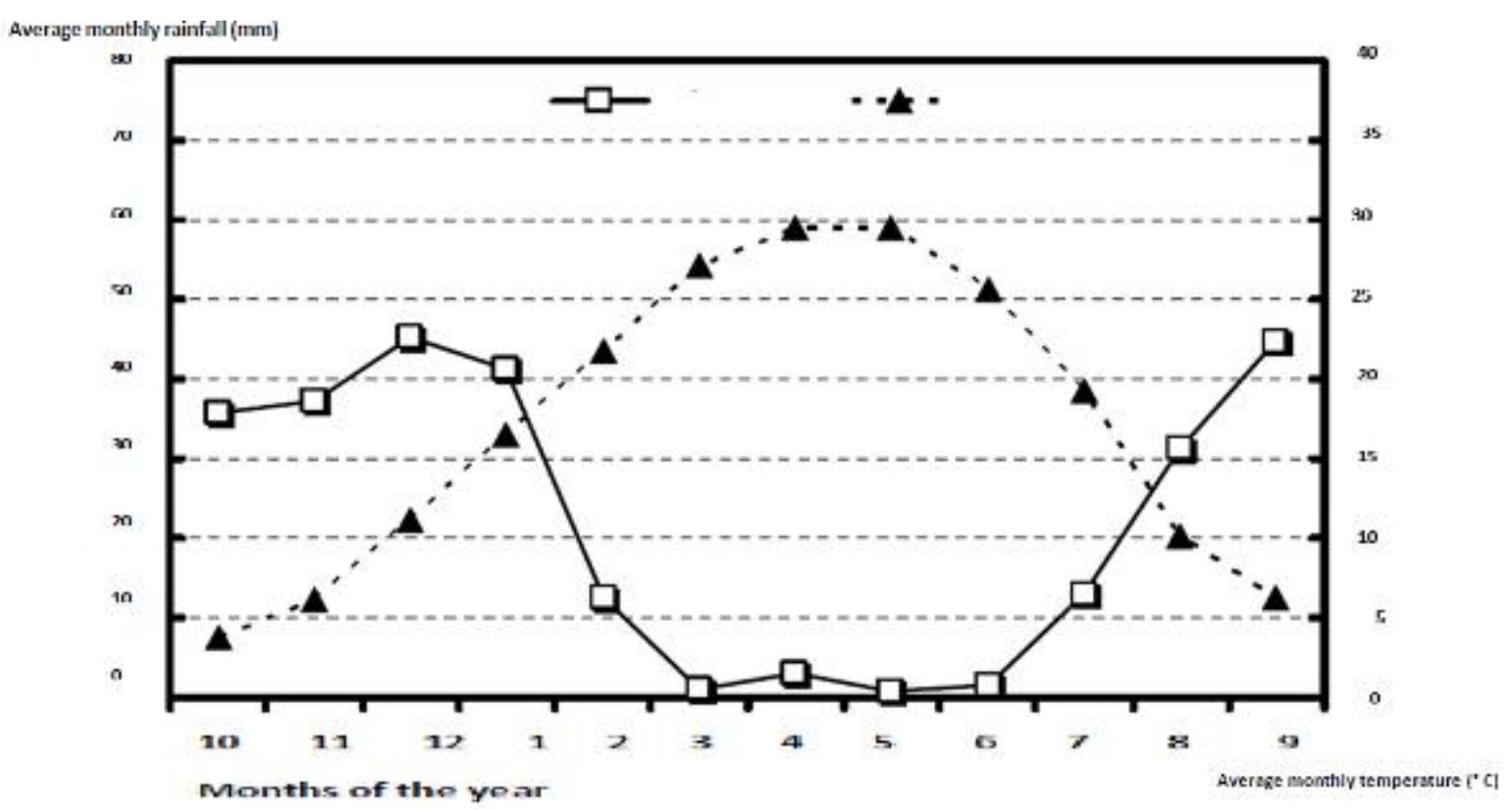

Fig.4. Hyetograph curve synoptic stations Cheetgar enjoyed the last 15 years

\section{DESIGN TRENDS}

In addition to the design plans to design this collection, Development of the plan is also important.For this purpose, the insertion of spaces on the site was carried out,The design plans were discussed at a later stage,Detailed site plan was completed. The design process is as follows. The first stage design: After selecting the desired site, the most important step in the development of sustainable architecture, Trees were placed on the site, to design done in a way that does not cut any tree.

The second phase of the design: Due to the topography of the site and the placement of trees, Spaces available on site for the staining was found.And the relationship of spaces, access, Private and public spaces is being humans and easily.

The third stage design: the next big idea is mounted and dismounted separate ways; So that means roadway access to all sites, and does not interfere with walking paths. For this purpose the roadway around the site were considered. The fourth stage design after the initial design of the site, the project was designed to do; for this purpose, because of the extent and magnitude of the series, a number of spaces are available on a less significant role, Blot and important spaces were designed for.

\section{CONCEPT}

The idea is intended for form design and plan buildings, According to the project, based on 
the psychology of forms has been made, According to the form circle or polygon to collectors and create a sense of community, Lobbies in the collection of this kind are planned. Designing a collection form is such that, In addition, consistent with the intended use of the building, in order from the entrance to the site, Gradually, square and rectangular forms in the office building started, In the midst of a combination of two of circles and squares, Is in public areas and passes through it, Next the square form of low buildings, And they will be added in the form of curves and circles. According to the psychology of forms, circular form symbolizes the sky and symptoms are the feeling, it is the best form for the series. People who are in this building, a very close relationship with their emotions. The general form of a curved surface formed from the two, that somehow evokes the concept of life, sunrise, Day and evening passes it, is that eventually, Twists in this form, and rising again brings us to the first point.

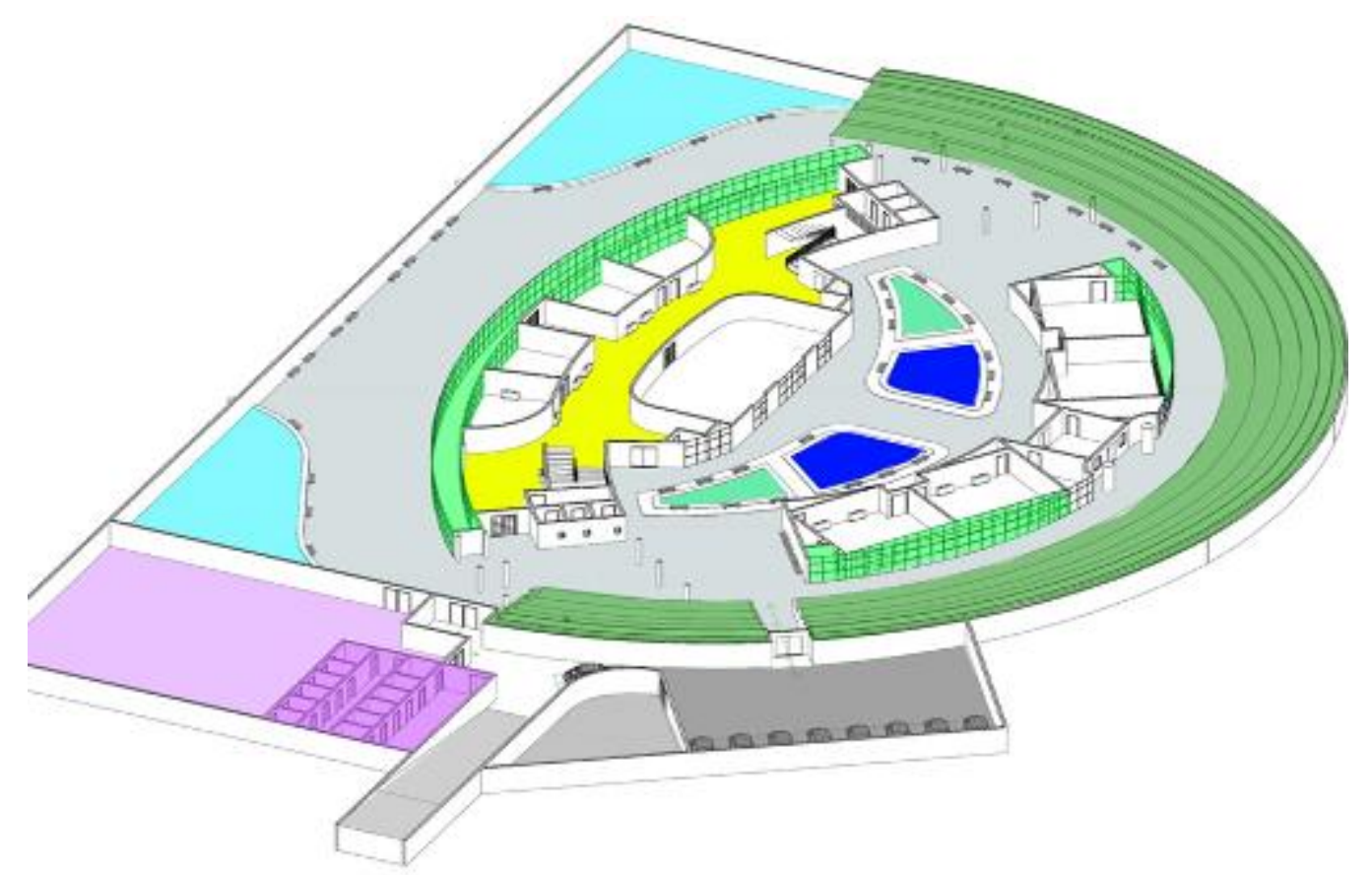

Fig.5. Completing the Basement 


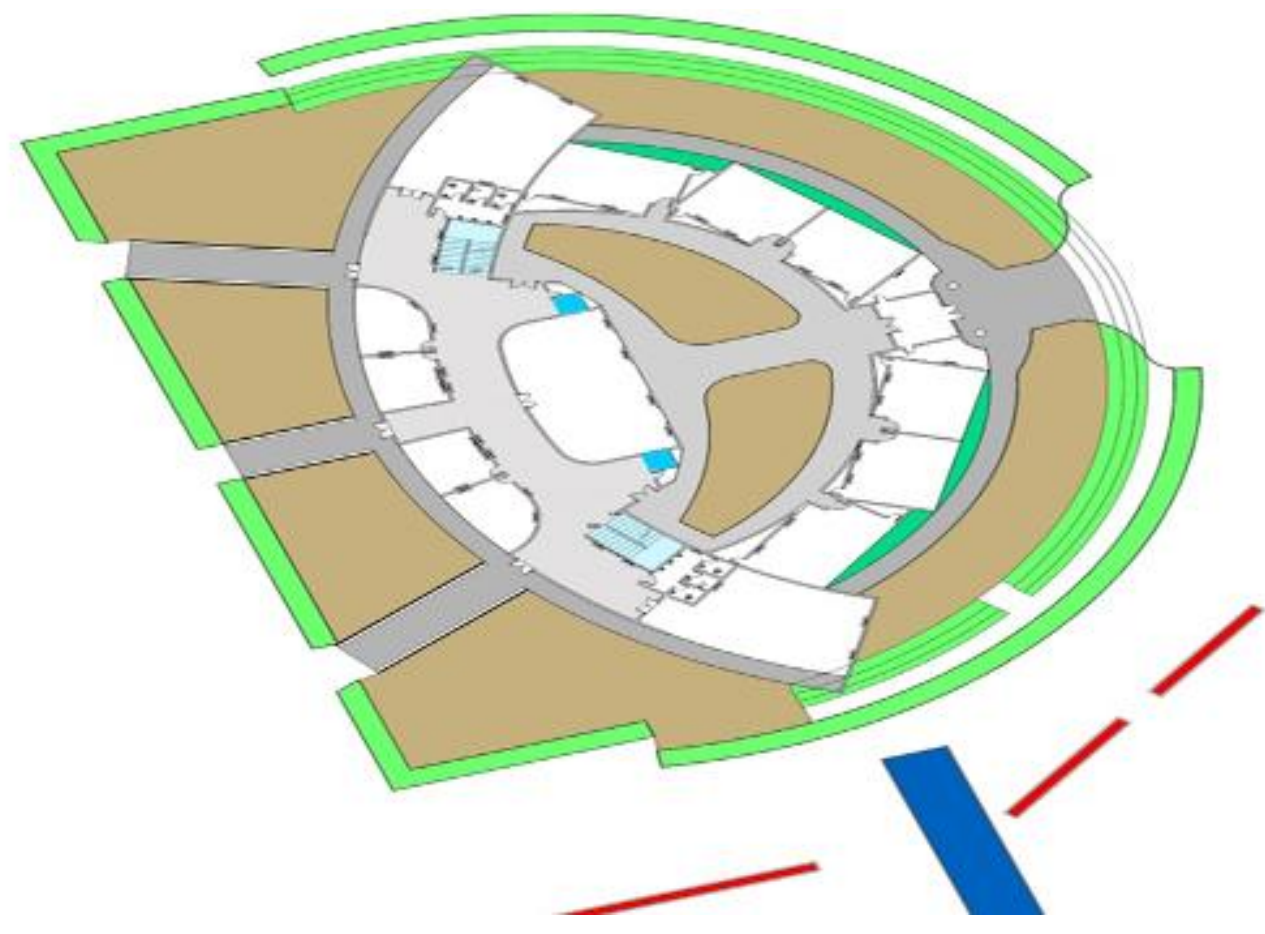

Fig.6. Completing the ground floor

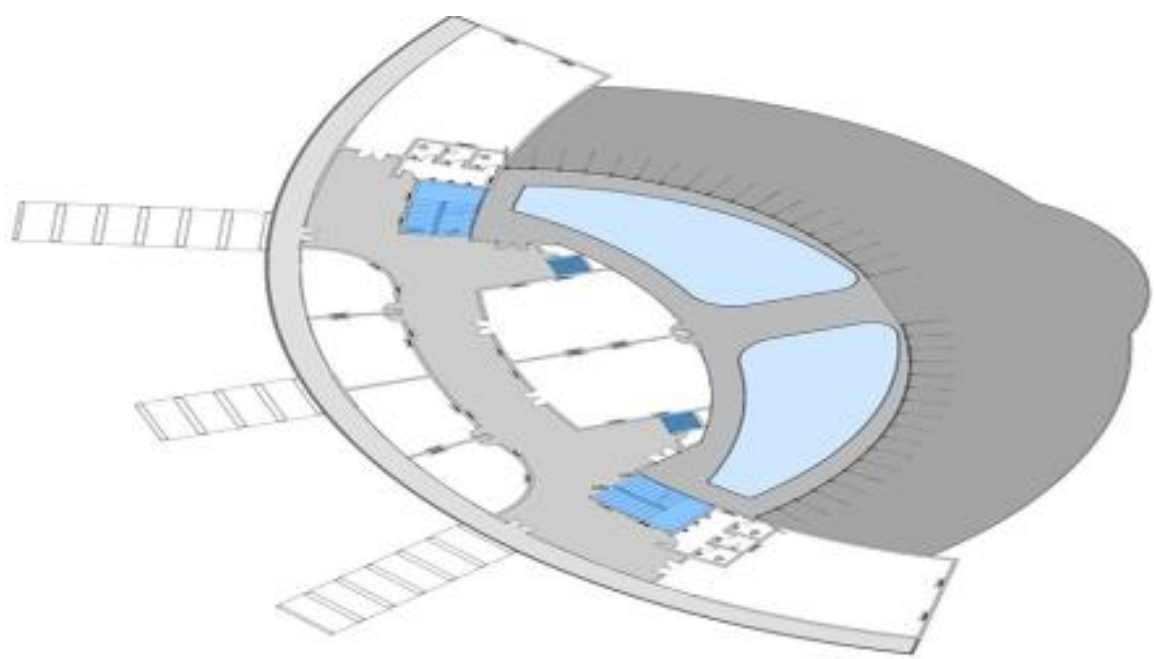

Fig.7. Completing the first floor 


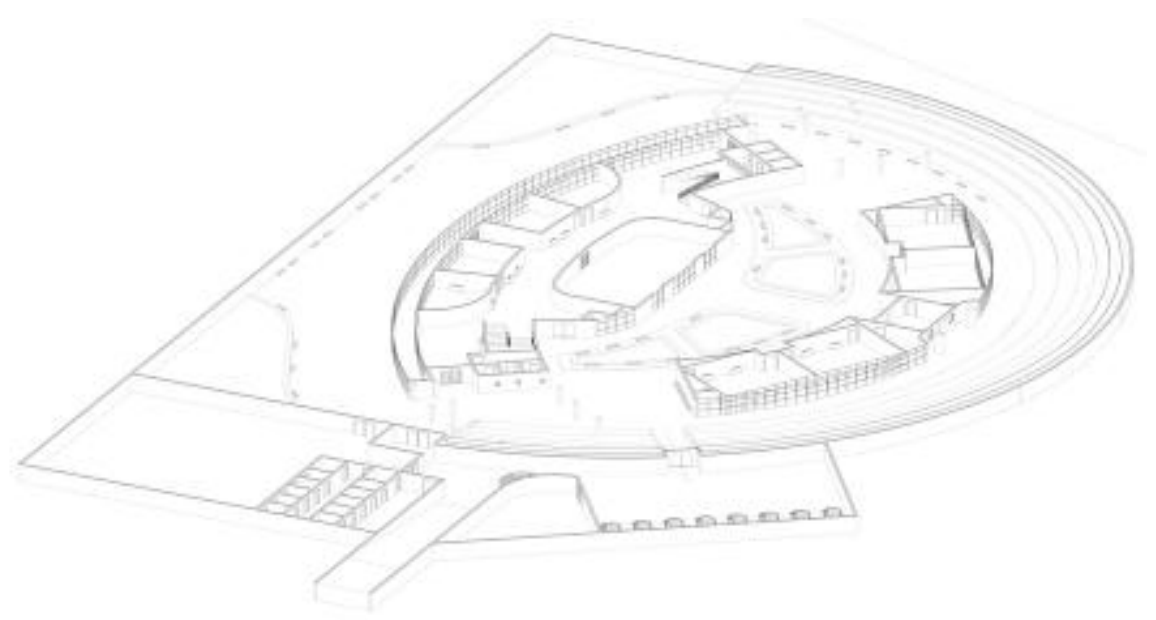

Fig.8. Cutting perspective basement

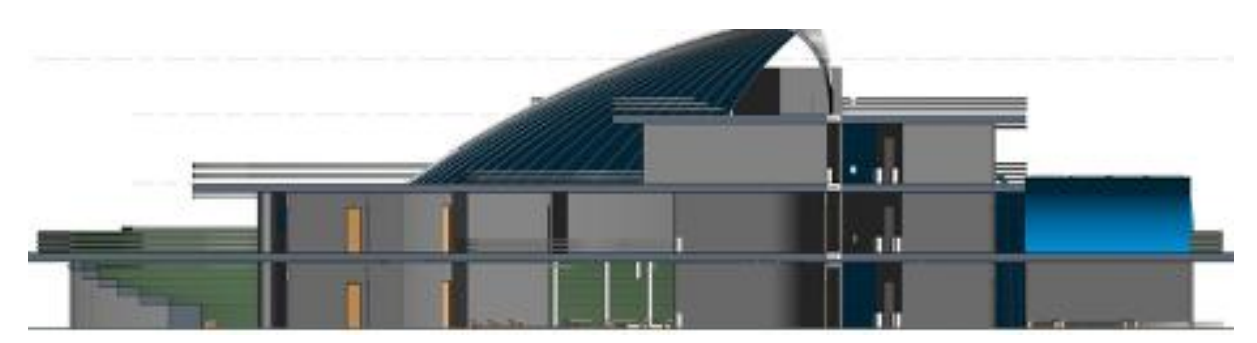

Section 1-1

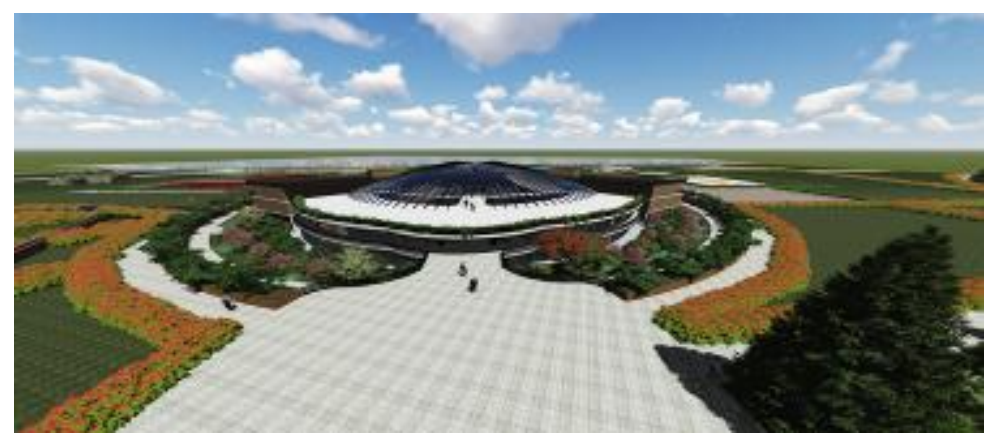

See the bird collection volume 


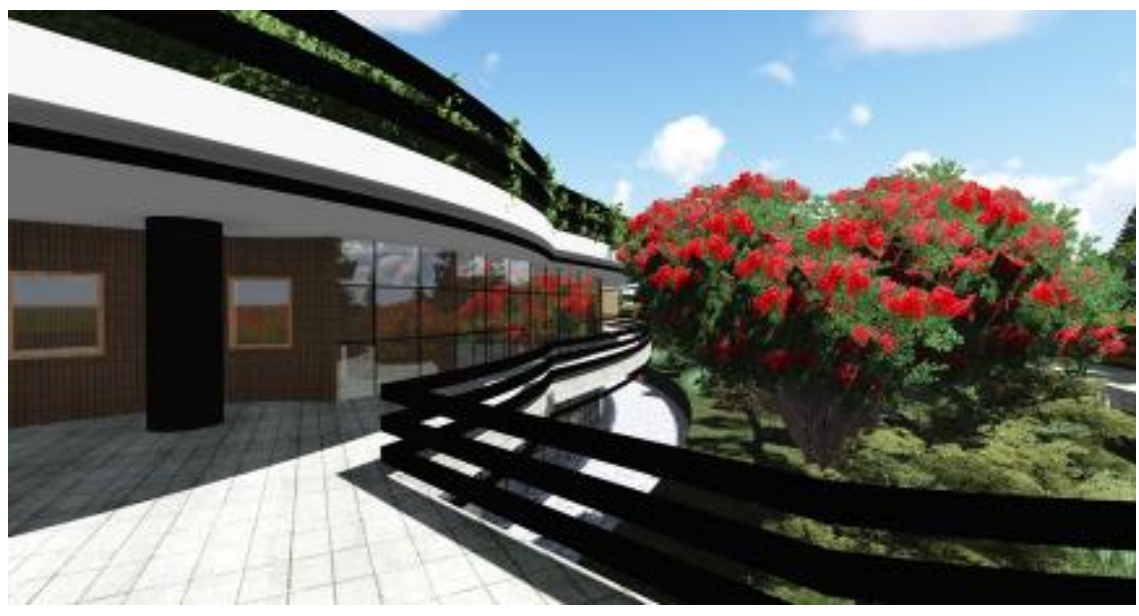

Fig.8. Human vision monitors are entering the set

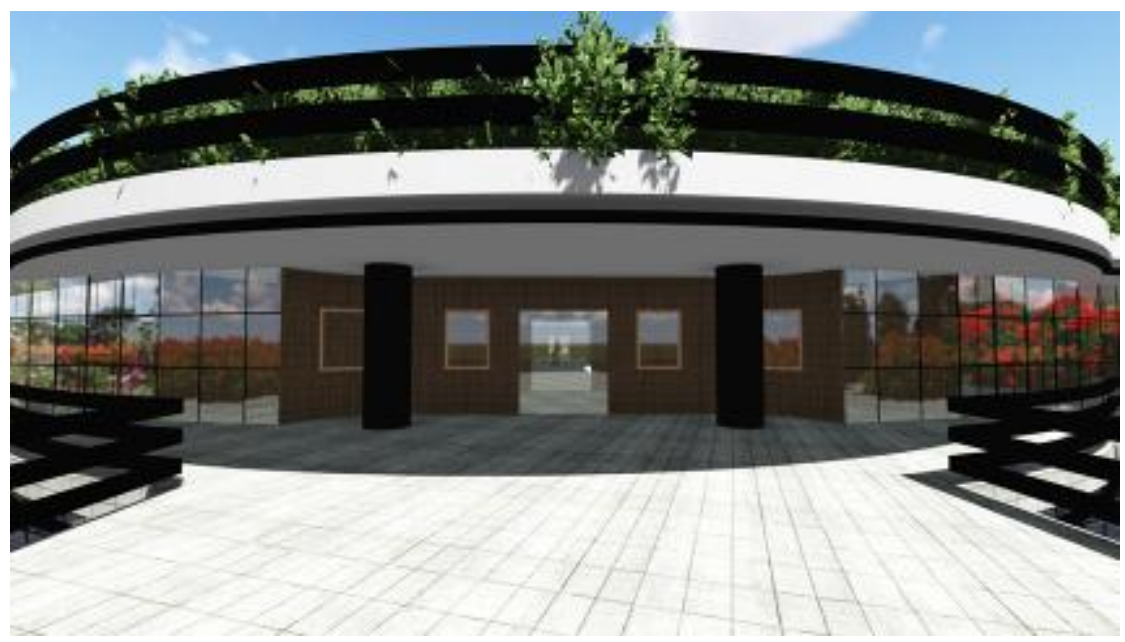

Fig.9. View of the main entrance

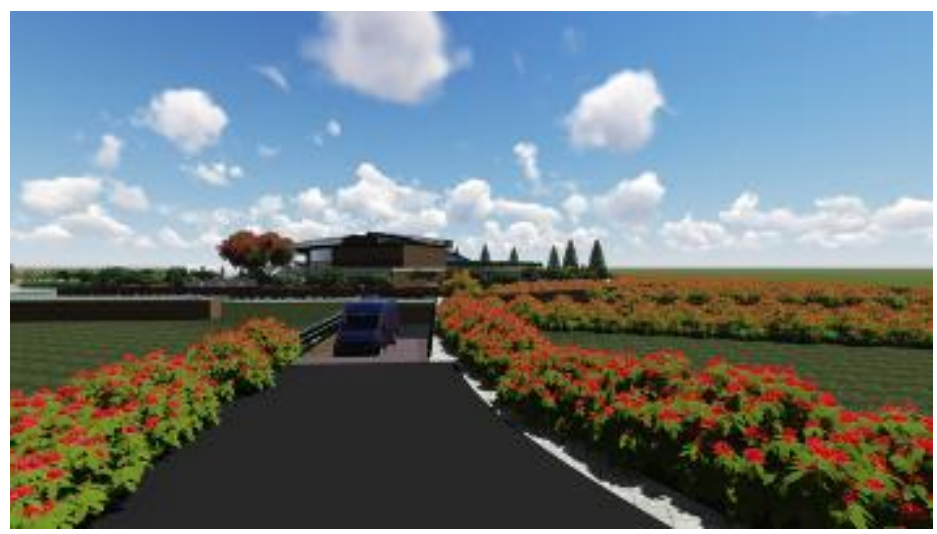

Fig.10. Parking ramp personnel, equipment and waste 


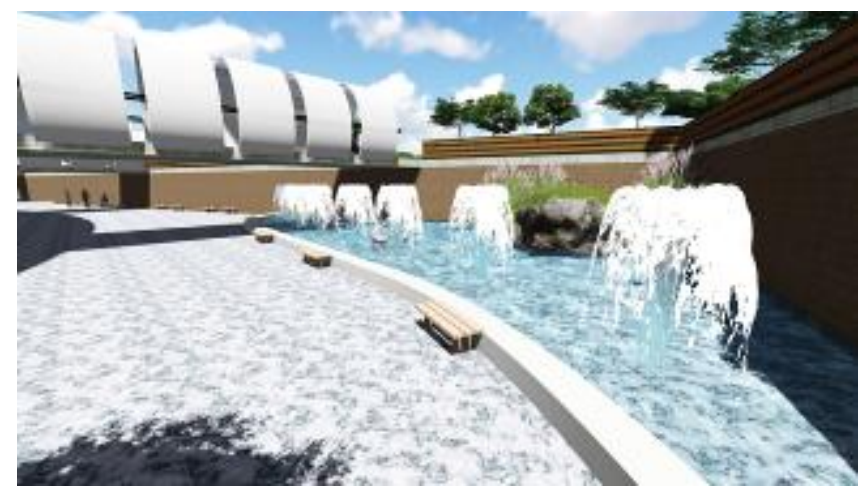

Fig.11. Fountain and greenness basement

\section{CONCLUSION}

Sustainability, including ways that cause less damage, the human environment, and this will remain the land and its riches, for future generations to be human. These solutions, He was just stating a new technology, and sometimes correct policy for a favorable development takes place; But the ultimate goal of all these solutions lead to a point. In the meantime, it is important to note, That just does not meet the knowledge needs stability; Sometimes a look at what our ancestors have used it, Very simple but effective ways to put our feet. Take a look at the past, Iran and materials used in its architecture, It also orders the construction techniques and arrow.

One of the best ways to minimize your verified, energy consumption and ultimately the sustainability of a building. It should also be borne in mind that stability, In architecture and urbanism, Because of the differences in geography and climate of each region, Studies and conditions of its own; in other words, Achieve stability architecture in every climate zone, Requires studies and solutions are specific to that area, And dispensing the same for all the world to achieve stability, Farce and it is impossible; So in any climatic regions have experienced a new and unique solutions.

The set design is based on scientific principles, Existing as well as similar examples and existing Bhrgyry, in the world and has initial plans to meet the proposed spaces, given. According to various aspects of sustainable development, And for production of electricity from renewable energy set, Another important aspect is the dominant design, The proposal is presented; Finally, to achieve a suitable model to build Health and development of villages in the vicinity of other cities and countries, The objectives and results are. 


\section{REFERENCES}

[1] Hosseini, SA, Health village approach utilizes the principles of sustainable architecture and smart, Siavash Timorese spread, MA, Azad University neighborhoods, neighborhoods, Persian date Ordibehesht 1395, pp. 49-50.

[2] Hosseini, SA, Health village approach utilizes the principles of sustainable architecture and smart, Siavash Timorese spread, MA, Azad University neighborhoods, neighborhoods 1395.s May 45.

[3] Hosseini, SA, Health village approach utilizes the principles of sustainable architecture and smart, Siavash Timorese spread, MA, Azad University neighborhoods, neighborhoods .ardybhsht 1395.s 123.

[4] Goldis Vahidi, compact city, urban forms, The first conference on sustainable urban development, pp. 7-8, 1390

[5] Bryman, A. And Bell, E, 2007, Business Research Methods, Oxford University Press 326-328.

[6] Campbell, S. (1997). Growing Cities, Green Cities, Just Cities? Urban Planning and the Contraddictions of Sustainable Development. Journal of American Planning Association, 62, 3: 296-312.

[7] Efficient energy consumption and operation management in a smart building with microgrid, Di Zhang a, Nilay Shah b, Lazaros G. Papageorgiou, Energy Conversion and Management 74 (2013) 209-222.

[8] Jabareen, Y. R. (2006). Sustainable Urban Forms: Their Typologies, Models, and Concepts. Journal of Planning Education and Research, 26, 38-52.

[9] Lélé, S. M. (1991). Sustainable Development: A Critical Review. World Development, 19, 6: 607-621.

[10] Stren, R., White, R., \& Whitney, J. (1992). Sustainable Cities. Urbanization and the Environment in International Perspective. Oxford: Westview Press.

[11] Stren, R., White, R., \& Whitney, J. (1992). Sustainable Cities. Urbanization and the Environment in International Perspective. Oxford: Westview Press.

[12] Tanguay, G. A., Rajaonson, J., Lefebvre, J. F., \& Lanoie, P. (2010). Measuring the sustainability of cities: An analysis of the use of local indicators. Ecological Indicators, 10: 407-418.

[13] The United Nations. (2002). Report of the World Summit on Sustainable Development. New York: United Nations Publications. 
[14] United Nations' Dep. of Economics and Social Affairs. (2010). 2009 Revision of World Population Prosepcts. New York: United Nations.

[15]Van Bueren, E., van Bohemen, H., \& Visscher, H. (. (2012). Sustainable Urban Environments. An Ecosystems Approach. Dodrecht: Springer.

[16]X. Guan, Zh. Xu, Q. Jia, ,’Energy-Efficient Buildings Facilitated by Microgrid “ IEEE Transactions on smart grid, vol. 1, pp. 243-252, December 2010.

How to cite this article:

Hoseini $S$ and Teimory S. Design health village with the approach of sustainable architecture and utilization of intelligent principles. J. Fundam. Appl. Sci., 2016, 8(3S), 366383. 